\title{
Os conceitos semânticos de afetação e de mudança de estado em uma análise construcional dos verbos do $\mathrm{PB}$ Affectdness and change of state semantic concepts in a constructional analysis of BP verbs
}

\begin{abstract}
RESUMO: Neste artigo, tomamos como objeto de estudo os conceitos semânticos de afetação e de mudança de estado com o intuito de evidenciarmos que eles não devem ser tratados como sinônimos, contrariamente ao que propõem alguns autores. Para tanto, analisamos, com base no quadro teóricometodológico da Gramática de Construções e da Semântica Lexical, cem verbos que denotam algum tipo de afetação ao seu argumento interno, em termos de suas propriedades semânticas e sintáticas e das construções de estrutura argumental em que podem ocorrer. Ao final, mostramos que os verbos de afetação mais ampla não participam de todas as construções que os verbos de mudança de estado instanciam, de modo que concluímos que toda mudança de estado acarreta afetação, mas o contrário não é necessariamente verdadeiro.
\end{abstract}

PALAVRAS-CHAVE: Gramática de construções. Construções de estrutura argumental. Verbos de afetação. Verbos de mudança de estado.

\begin{abstract}
In this paper we analyze affectdness and change of state semantic concepts in order to show that they should not be treated as synonyms, in contrast to some authors proposals. Therefore, we study, based on Construcional Grammar theoretical and methodological framework, one hundred verbs that denote their internal argument affectedness. We analyze their semantic and syntactic properties and also argument structure constructions that they can occur. We show that affectedness verbs, in a broad sense, do not participate of all constructions that change of state verbs instantiate. So, we conclude that every change of state entails affectedness, but the opposite is not necessarily true.
\end{abstract}

KEYWORDS: Construcional grammar. Argument structure constructions. Affectedness verbs. Change of state verbs.

\section{Introdução}

Anderson (1979), Roberts (1985) e Beavers (2011) definem o conceito de afetação como uma mudança que ocorre em um participante de um evento. No entanto, ao observarmos os verbos que trazem consigo essa noção, vemos que há uma diferença básica entre eles:

(1) O capitão do mato chicoteou o escravo.

(2) A arrumadeira espanou os móveis.

\footnotetext{
* Aluna de doutorado do Programa de Pós-Graduação em Estudos Linguísticos da Faculdade de Letras da UFMG. A autora agradece as sugestões feitas pela Profa. Dra Sueli Coelho.
} 
(3) O povo apedrejou o bandido.

(4) O menino quebrou o vaso de flor.

(5) Miriam hidratou a pele de Lívia.

(6) Ana machucou Maria.

Nos exemplos acima, todos os argumentos internos são entidades afetadas pelas ações descritas pelos verbos. Porém, apenas quebrar, hidratar e machucar acarretam o sentido de ficar (ou tornar-se) estado, nos quais o argumento interno verbal sofre uma mudança (de estado) e o adjetivo que denota o estado é relacionado ao verbo (MCCAWLEY, 1968; LAKOFF, 1970; DOWTY, 1979, PARSONS, 1990; CANÇADO; GODOY; AMARAL, 2013).

(7) O vaso de flor ficou quebrado.

(8) A pele de Lívia ficou hidratada.

(9) Maria ficou machucada.

(10) *O escravo ficou chicoteado.

(11) * Os móveis ficaram espanados.

(12) *O bandido ficou apedrejado.

A partir daí, baseadas em Fillmore (2003 [1970]) e Cançado, Godoy e Amaral (2013), a nossa hipótese é de que o conceito de afetação não pode ser definido como equivalente ao de mudança. O primeiro seria uma noção mais ampla, enquanto o segundo seria um subtipo do primeiro, ou seja, um tipo mais específico de afetação, caracterizado por propriedades semânticas e sintáticas específicas, de modo que ambos os conceitos não podem ser tomados como sinônimos.

Assim, o nosso objetivo é analisar os conceitos de afetação e de mudança propostos na literatura e aplicá-los a uma série de verbos do português brasileiro (PB) com o intuito de tentarmos validar nossa hipótese inicial. Para tanto, selecionamos, através dos trabalhos de Cançado, Godoy e Amaral (2013), de Meirelles e Cançado (2015) e de Cançado, Amaral e Meirelles (em prep.), cem verbos que denotam algum tipo de afetação ao seu argumento interno e que serão descritos em termos de suas propriedades semânticas e sintáticas e das construções de estrutura argumental (GOLDBERG, 1995) em que podem ocorrer.

Nosso trabalho se justifica, uma vez que os conceitos de afetação e mudança parecem não estar tão claros na literatura, sendo tratados como sinônimos, mesmo apresentando diferenças semânticas, como mostrado nas sentenças de (7) a (12).

Este artigo faz a junção de duas linhas de pesquisa: a Semântica Lexical, pois trata de conceitos teóricos importantes para os estudos dessa área, e a Gramática de Construções, pois 
distingue esses conceitos (afetação e mudança semântica) através das construções de estrutura argumental em que os verbos que os denotam podem ocorrer.

Na seção 2 apresentamos uma breve exposição teórica sobre a Semântica Lexical e a Gramática de Construções. A seção 3 descreve as propriedades semânticas de afetação e de mudança de estado na literatura. A quarta seção traz a apresentação e a análise dos dados, além da nossa proposta para a definição dos conceitos de afetação e de mudança de estado. A última seção conclui o artigo.

\section{Semântica lexical e gramática de construções}

Durante muito tempo, na linguística estruturalista e gerativista (BLOOMFIELD, 1933; CHOMSKY, 1957 e trabalhos subsequentes), o léxico foi tratado como um simples repositório de palavras, papéis temáticos e exceções gramaticais, enquanto a gramática consistia (e ainda consiste para algumas teorias, principalmente as de cunho gerativista) em um sistema computacional que determina os princípios de combinação de palavras para que sejam formadas sentenças.

No entanto, a importância do léxico para as teorias linguísticas tem se tornado cada vez mais clara, de modo que abordagens lexicalistas estão mais presentes nas discussões sobre a aquisição do nosso conhecimento linguístico, como pode ser visto em Fillmore (2003a [1970], $2003 b$ [1971]), Kiparsky (1982, 1985), Pinker (1989), Jackendoff (1983, 1990), Levin (1993), Levin e Rappaport Hovav (1992, 1995, 2005, dentre outros trabalhos), Pustejovsky (1995), Wunderlich (1997, 2012), Cançado e Godoy (2012), Cançado, Godoy e Amaral (2013), entre outros.

Dentre as linhas de pesquisa que defendem a existência de um léxico organizado, podemos destacar a Semântica Lexical, que estuda a representação mental do significado, focando na definição da significação verbal. Os estudos dessa área partem do pressuposto de que a realização sintática dos argumentos verbais é motivada pela semântica do verbo (PINKER, 1989; LEVIN; RAPPAPORT HOVAV, 1992, 1995, e trabalhos subsequentes; WUNDERLICH，1997，2012; CANÇADO，2005，2010; CANÇADO; GODOY，2012; CANÇADO; GODOY; AMARAL, 2013; entre outros). Assim, o objetivo principal dos estudos em Semântica Lexical, que assumem essa hipótese, é propor representações semânticas para os verbos que possam servir de base para a explicação de sua sintaxe. Essas representações recebem o nome de estrutura argumental (CANÇADO; GODOY, AMARAL, 2013) e podem 
ser dadas através de grades temáticas ou da linguagem de decomposição de predicados primitivos ${ }^{1}$.

A Gramática de Construções, por sua vez, é uma das vertentes teóricas da Linguística Cognitiva, tendo surgido a partir dos trabalhos de Lakoff (1987), de Fillmore et al (1988), de Goldberg (1995), entre outros. Ela parte do pressuposto de que estudar a língua equivale a estudar a mente humana e possui uma visão não modular da linguagem, defendendo a existência de um continuum entre a sintaxe e o léxico. Nesse aspecto, a Gramática de Construções e a Semântica Lexical apresentam pontos de vista distintos, mas não contraditórios: enquanto a primeira propõe um continuum entre o léxico e a sintaxe, a segunda advoga a favor de um componente lexical totalmente organizado e estruturado. Porém, ambas defendem a existência de uma semântica cognitiva (e não apenas interpretativa, como propõe a Gramática Gerativa) que está na base dos processos linguísticos.

Para as teorias construcionais, as unidadés linguísticas mínimas são as construções, que podem ser definidas como um pareamento entre forma (sintaxe) e significado (semântica), e que são instanciadas por unidades simples, como morfemas, ou complexas, como as orações (GOLDBERG, 1995). Nesse sentido, qualquer padrão é reconhecido como construção, desde que algum aspecto de sua forma ou função não seja previsível de suas partes componentes ou de outras construções já existentes.

O trabalho de Goldberg (1995) foca no estudo das chamadas "construções de estrutura argumental", que são compostas por um verbo e seus argumentos. No entanto, diferentemente da Semântica Lexical, a autora propõe que o verbo não é o único predicador de uma construção, uma vez que há elementos que são argumentos dessa última e não do item verbal. Peguemos, como o exemplo, o verbo pular. Ele é um verbo monoargumental, ou seja, pede apenas um argumento (no caso, externo) para ter o seu sentido saturado: O menino pulou. Porém, ele pode ocorrer em sentenças que trazem um sintagma que expressa a origem ou alvo do pulo, como em o menino pulou da camal o menino pulou na cama. Os sintagmas preposicionados da cama e na cama não fazem parte da estrutura argumental do verbo, pertencendo apenas à construção.

\footnotetext{
${ }^{1}$ Hoje é assumido que o significado verbal é mais bem representado através da linguagem de decomposição de predicados primitivos (DOWTY, 1979; JACKENDOFF, 1983, 1990; PINKER, 1989; LEVIN; RAPPAPORT HOVAV, 1995, 2005; RAPPAPORT HOVAV; LEVIN, 1988; BEAVERS, 2010; CANÇADO; GODOY; AMARAL, 2013), pois essa apresenta mais informações a respeito do verbo do que uma grade temática, uma vez que traz, além da relação semântica entre o verbo e seus argumentos, informações do evento como um todo. Para uma visão mais detalhada sobre as vantagens do uso da linguagem de decomposição de predicados na representação lexical, ver Cançado, Godoy e Amaral (2013) e Meirelles (2013).
} 
Dessa forma, Goldberg (1995) propõe a distinção entre papéis participantes e papéis argumentais $^{2}$. Os primeiros correspondem aos papéis que preenchem o sentido verbal, enquanto os segundos são elementos que fazem parte da construção, mas que não saturam o verbo. Todo papel participante tem um papel argumental correspondente, mas o contrário não é verdadeiro. Dessa forma, na construção o menino pulou da/ na cama, o menino é, ao mesmo tempo, papel participante e papel argumental, enquanto da/ na cama é apenas papel argumental ${ }^{3}$.

Neste artigo, trabalhamos com os verbos de afetação e de mudança do PB com o intuito de diferenciarmos esses dois conceitos semânticos, tidos como sinônimos na literatura, por meio das construções de estrutura argumental em que os verbos que os apresentam podem ou não ocorrer. Juntamente com Goldberg (1995), assumimos que não só argumentos verbais fazem parte das construções e que a representação lexical dos verbos fornecida pelos estudos em Semântica Lexical corresponde ao pólo semântico das construções (GOLDBERG, 1995; RAPPAPORT HOVAV; LEVIN, 1998a, 2001). Trataremos da representação semântica das construções em termos de papéis temáticos, e não da linguagem de decomposição de predicados primitivos, pois os primeiros nos permitem propor representações mais simplificadas, enquanto a segunda é utilizada para descrições semânticas mais finas das classes verbais de uma língua, o que não é objetivo de nosso trabalho.

\section{Os conceitos semânticos de afetação e de mudança}

O conceito de afetação é definido, por Anderson (1979) e por Roberts (1985), como a propriedade de um argumento que passa por uma mudança de estado ${ }^{4}$ durante o decorrer do evento descrito pelo verbo. Nesse sentido, quebrar e machucar, por exemplo, seriam verbos prototípicos de afetação, uma vez que seu argumento interno sofre uma mudança de estado.

(5) O menino quebrou o vaso de flor.

\footnotetext{
2 A distinção entre papéis participantes e papéis argumentais é consensualmente assumida por autores que trabalham com a Gramática de Construções. Para o PB podemos citar, por exemplo, os trabalhos de Ferrari (2010), Cunha (2013), Ciríaco (2014), entre outros.

${ }^{3}$ Segundo Ferrari (2010, p. 160), os papéis argumentais "constituem contribuição da construção apenas". A autora dá o exemplo do verbo cabecear (o jogador cabeceou a bola para o gol) que, segundo ela, apresenta apenas um papel participante que se funde com o papel argumental de causa (o jogador) e dois papéis que são apenas argumentais, sendo instanciados por contribuição da construção: o tema (a bola) e o alvo (para o gol).

${ }^{4}$ Embora autores como Hopper e Thompson (1980) e Givón (2011) apresentem uma definição mais ampla do conceito de afetação, neste artigo nos delimitaremos às análises que tratam o conceito de afetação como equivalente ao de mudança de estado.
} 
(6) Ana machucou Maria.

Em (5), o vaso de flor passa do estado de não quebrado para quebrado, enquanto, em (6), Maria muda de não machucada para machucada.

Tenny (1987), já percebendo as complicações de se definir o conceito de afetação baseado no de mudança de estado, propõe que o primeiro deve ser descrito a partir de propriedades aspectuais do verbo. Para a autora, "a afetação deve ser definida como a propriedade de um verbo que descreve uma situação ou um acontecimento que pode ser delimitado pelo argumento direto desse verbo" ${ }^{5}$ (TENNY, 1987, p. 75). Essa definição dá conta de explicar alternâncias aspectuais com verbos como comer, ler, escrever, entre outros, uma vez que $O$ João comeu muito seria uma sentença que denota uma atividade ${ }^{6}$ e $o$ João comeu uma maçã denota um evento de accomplishment devido à delimitação imposta pelo argumento interno. O mesmo vale para as sentenças o João leu muito/ o João leu um livro e o João escreveu muito/ o João escreveu uma carta. Além disso, na proposta da autora, verbos de movimento também podem ter um sintagma preposicionado que os delimitam, como em Henrique correu até a escola e a bola rolou até o pé do morro.

Contudo, Beavers (2011) retoma as ideias de Anderson (1979) e Roberts (1985) e define afetação "como uma mudança em um participante do evento" (BEAVERS, 2011, p. 1) que se movimenta, metaforicamente, por uma determinada escala. Dessa forma, a afetação varia em graus, dependendo se o verbo especifica ou não até que ponto da escala o seu argumento interno deve se mover. Na hierarquia proposta pelo autor, existem quatro graus de afetação: mudança quantizada, não quantizada, mudança potencial e mudança não especificada.

A mudança quantizada descreve o movimento de um paciente $y$ de um estado inicial a um estado final na mesma escala como é o caso de quebrar e de machucar. Os eventos de mudança não quantizada descrevem situações em que não há a especificação de que $y$ chega a um ponto final na escala. De acordo com Amaral (2015), afundar (o pirata afundou o navio no mar) seria um verbo de mudança não quantizada, pois “em um evento descrito por esse verbo,

\footnotetext{
${ }^{5}$ Do original: "affectedness may be defined as the property of a verb, such that it describes a situation or happening that can be delimited by the direct argument of the verb" (tradução nossa).

${ }^{6}$ Vendler (1967) propõe a existência de quatro classes aspectuais do tipo lexical: atividades, estados, achievements e accomplishments. Os verbos de atividade descrevem ações monoeventivas que se desenvolvem no tempo, sem ter um determinado ponto de conclusão. Vale dizer que são agentivos, dinâmicos e homogêneos, na medida em que qualquer de suas partes é da mesma natureza que o todo. Já os verbos de accomplishment caracterizam-se por serem verbos bieventivos e télicos, ou seja, por indicarem uma ação que se desenvolve no tempo e possui um ponto de culminação (DOWTY, 1979).
} 
existe uma escala de profundidade na qual $y$ se move, mas não há a especificação de até que ponto $y$ se move, nem o acarretamento de que $y$ deve se mover até o ponto final de $s^{7,}$ (AMARAL, 2015, p. 21).

O terceiro tipo de afetação é a mudança potencial, que descreve eventos que podem causar a mudança de $y$, mas não necessariamente a causam. Um exemplo de verbo de afetação potencial seria chicotear, pois em uma sentença como o capitão do mato chicoteou o escravo, o paciente y (o escravo) pode passar por uma mudança física, mas essa não é codificada pelo verbo. Por fim, na mudança não especificada não existe uma escala pela qual y poderia se mover, pois não há a possibilidade de ocorrer nenhum tipo de mudança. Os eventos de mudança não especificada são representados por verbos como vender, alugar e comprar, pois a venda, o aluguel e a compra de uma casa não resultam em nenhum tipo de mudança na casa, de modo que essa não se move fisicamente em uma trajetória, nem muda de estado (AMARAL, 2015).

Jackendoff (1990), por sua vez, propõe a existência de uma função AFF (afetar), que codifica os papéis de agente e de paciente, em sua semântica conceptual. $\mathrm{O}$ autor também propõe um teste que evidencia a presença de afetação em um evento, de modo que eventos desse tipo completam adequadamente as sentenças o que aconteceu com o y foil o que o $x$ fez com y foi. Dessa forma, quebrar seria um verbo de afetação, pois completa as sentenças: $o$ que aconteceu com o vaso de flor foi que o menino o quebrou/ o que o menino fez com o vaso de flor foi quebrá-lo.

O conceito de mudança de estado, contrariamente ao de afetação, apresenta um tratamento mais uniforme na literatura, uma vez que vários autores concordam que o sentido dos verbos de mudança de estado carrega o metapredicado BECOME, que representa a mudança lexicalizada pelo verbo, associado a uma raiz $<$ STATE $>^{8}$ (RAPPAPORT HOVAV; LEVIN, 1998a, 1998b, 2010; LEVIN, 1999; HALE; KEYSER, 1993, 2002; PARSONS, 1990; PESETSKY, 1995).

Segundo McCawley (1968), Lakoff (1970), Dowty (1979) e Parsons (1990), verbos que denotam uma mudança de estado acarretam o sentido de 'ficar/ tornar-se estado', onde o argumento interno verbal sofre uma mudança (de estado) e o adjetivo que denota o estado é relacionado ao verbo. Assim, como mostramos em (4) e em (7), o verbo quebrar, por exemplo,

\footnotetext{
${ }^{7}$ O símbolo $s$ significa escala (BEAVERS, 2011; AMARAL, 2015).

${ }^{8} \mathrm{Na}$ linguagem de decomposição de predicados primitivos os metapredicados são elementos recorrentes no sentido de uma classe de verbos, enquanto a raiz representa o sentido idiossincrático de cada verbo. No entanto, a categoria ontológica das raízes (estado, lugar, coisas, eventos) é comum a toda uma classe verbal.
} 
acarreta uma mudança de estado ao seu argumento interno, uma vez que uma sentença como $o$ menino quebrou o vaso de flor acarreta que o vaso de flor ficou quebrado.

Outra característica importante dos verbos de mudança de estado é que eles são causativos (CANÇADO, GODOY, AMARAL, 2013), de modo que a causa (primitivo CAUSE) é definida como uma relação entre dois subeventos descritos pelo mesmo verbo (DOWTY, 1979; PINKER, 1989; PARSONS, 1990; PUSTEJOVSKY, 1995; WUNDERLICH, 1997; LEVIN; HAPPAPORT HOVAV, 1999). Dessa forma, esses verbos possuem o aspecto lexical de accomplishment e a sua natureza causativa é evidenciada através do teste com o advérbio quase (MORGAN, 1969).

(13) a. O menino quase quebrou o vaso de flor.

b. O que o menino quase fez foi quebrar o vaso de flor.

c. O que o menino fez foi quase quebrar o vaso de flor.

Em (13b) temos a leitura de o que menino nem começou a agir, enquanto em (13c) entendemos que o menino agiu, mas não alcançou o resultado esperado, ou seja, não conseguiu quebrar o vaso de flor.

Baseadas nessas informações, Cançado, Godoy e Amaral (2013) fazem um minucioso levantamento dos verbos de mudança no PB e concluem que essa língua possui 682 verbos de mudança de estado, que se dividem em quatro subclasses de acordo com o tipo de sujeito que apresentam e com a sua transitividade básica: verbos de mudança de estado estritamente volitivos, que aceitam apenas um agente como sujeito (estatizar, nacionalizar); verbos opcionalmente volitivos, que aceitam tanto um agente como uma causa como sujeito (quebrar, machucar); verbos não volitivos, que só aceitam uma causa como sujeito (preocupar, cansar); e verbos incoativos, que são basicamente intransitivos (amadurecer, azedar). No entanto, não fazemos essa distinção em nosso trabalho. Selecionamos apenas exemplos de verbos de mudança de estado opcionalmente volitivos, pois além de essa ser a classe mais numerosa (436 verbos), também abarca os dois tipos de sujeitos: agente e causa. Os verbos de afetação mais ampla foram selecionados através dos trabalhos de Meirelles e Cançado (2015) e Cançado, Amaral e Meirelles (em prep.). 


\section{Apresentação e análise dos dados}

Como vimos na seção anterior, Jackendoff (1990) propõe que os verbos de afetação completam adequadamente a sentença o que ox fez com y foi, onde $y$ denota o argumento interno verbal afetado e $x$ a entidade que desencadeia essa afetação. De fato, todos os cem verbos por nós analisados passam nesse teste proposto pelo autor, o que evidencia que possuem a propriedade semântica afetação em seu significado.

(14) O que o capitão do mato fez com o escravo foi chicoteá-lo.

(15) O que a arrumadeira fez com os móveis foi espaná-los.

(16) O que o povo fez com o bandido foi apedrejá-lo.

(17) O que o menino fez com o vaso de flor foi quebrá-lo.

(18) O que Miriam fez com a pele de Lívia foi hidratá-la.

(19) O que Ana fez com Maria foi machucá-la.

No entanto, como mostramos na introdução deste artigo, os verbos de afetação apresentam diferenças semânticas entre si. Além da diferença de acarretamento (exemplos de 7 a 12), esses verbos se distinguem em relação ao seu aspecto lexical. Vejamos alguns exemplos:

(20) a. Ana quase machucou Maria.

a'. O que Ana quase fez foi machucar Maria.

a'. O que Ana fez foi quase machucar Maria.

(21) a. O capitão do mato chicoteou o escravo.

a'. O que o capitão do mato quase fez foi chicotear o escravo.

a". \# O que o capitão do mato fez foi quase chicotear o escravo ${ }^{9}$.

A sentença em (20a) apresenta duas leituras, uma de que Ana nem agiu (20 a') e outra de que Ana agiu, mas não alcançou o resultado desejado (20 a" "). Já o verbo chicotear apresenta apenas a primeira leitura, ou seja, a de que o capitão do mato nem agiu, uma vez que a segunda leitura (21 a') nos soa estranha semanticamente. Portanto, verbos do tipo machucar (quebrar, hidratar) denotam accomplishments, enquanto verbos do tipo chicotear denotam atividades.

Fillmore (2003 [1970]) já chamava atenção para a existência de uma diferença semântica entre os verbos de afetação. Através de um estudo dos verbos hit 'atingir' e break 'quebrar', o autor mostra que apenas verbos do tipo break acarretam uma mudança de estado

\footnotetext{
${ }^{9} \mathrm{O}$ símbolo \# indica que a sentença é malformada semanticamente.
} 
para o seu argumento interno, enquanto verbos de tipo hit não o fazem. Estes descrevem um tipo de afetação mais ampla e por isso não podem ser representados por uma estrutura contendo o primitivo BECOME e a raiz $<$ STATE $>$ (FILLMORE, 2003 [1970]; AMARAL, 2015).

Até aqui, vimos que existem diferenças semânticas entre os verbos de afetação, mas ainda não apontamos nenhuma diferença sintática entre eles, de modo que, a priori, poderíamos pensar que não há motivos para diferenciar os conceitos de afetação e de mudança, uma vez que esses se distinguem apenas por questões semânticas muito finas, mas que são irrelevantes para determinar sua sintaxe. Porém, daqui em diante, mostraremos que esses verbos variam em relação às construções de estrutura argumental (GOLDBERG, 1995) que instanciam, o que evidencia a necessidade de afetação e de mudança serem tratadas como duas noções distintas.

Todos os cem verbos por nós analisados participam da construção que denominamos “construção transitiva de afetação". Essa pode ser representada da seguinte forma de acordo com o modelo de representação de construções de estrutura argumental proposto por Goldberg (1995):

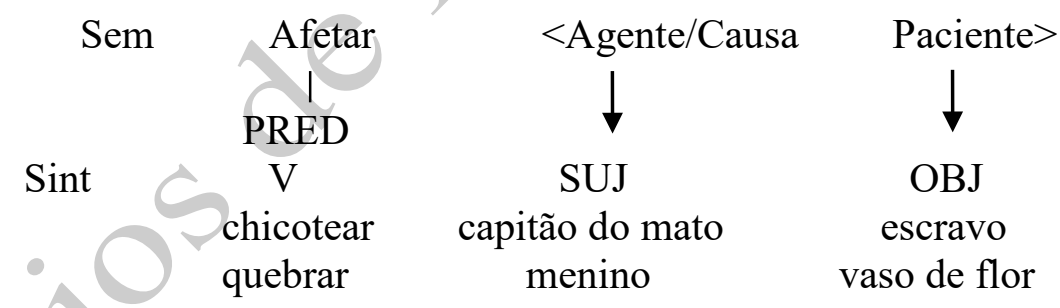

No entanto, utilizaremos uma forma de representação mais simplificada, baseada no trabalho de Perini (2008).

(23) $\left[\mathrm{SN}_{\text {Agente/Causa }} \mathrm{V} \text { SN Paciente }\right]^{10}$

O capitão do mato chicoteou o escravo.

A arrumadeira espanou os móveis.

O povo apedrejou o bandido.

O menino/ a queda quebrou o vaso de flor.

Miriam/ a aplicação de produtos dermatológicos hidratou a pele de Lívia.

Ana/ a queda machucou Maria.

\footnotetext{
${ }^{10}$ Estamos tratando como "paciente" qualquer entidade afetada por uma ação, mesmo que o evento não acarrete nenhum tipo de mudança para os seus participantes.
} 
Em (23), os dois sintagmas nominais (SNs) são, ao mesmo tempo, argumentos do verbo e da construção. É importante ressaltar que Perini (2008) e Goldberg (1995) não fazem a distinção entre os papéis temáticos de Agente e Causa. No entanto, neste trabalho, seguindo as evidências dadas por Fillmore (2003 [1970]) e as propostas de Cançado (2013) e de Cançado, Godoy e Amaral (2013), argumentamos que essa distinção é relevante. Esses dois últimos trabalhos, em consonância com o de Dowty (1979), mostram que somente agentes podem manipular um instrumento, o que faz com que a inserção do mesmo nas sentenças evidencie a agentividade do argumento externo verbal:

(24) a. Miriam hidratou a pele de Lívia com um bom creme. (sujeito Agente com adjunto Instrumento)

b. O tratamento hidratou a pele de Lívia. (sujeito Causa)

c. \#O tratamento hidratou a pele de Lívia com um creme. (sujeito Causa com adjunto Instrumento)

Além disso, Cançado, Godoy e Amaral (2013) mostram que apenas argumentos que recebem o papel temático de Causa podem aparecer em posição de adjunção, especificados pela preposição com:

(25) a. A pele de Lívia (se) hidratou com o creme. (Causa em posição de adjunção) b. \#A pele de Lívia (se) hidratou com a Miriam. (Agente em posição de adjunção)

A partir daí, quando propomos a representação [SN Agente/Causa $\quad \mathrm{V} \quad \mathrm{SN}$ Paciente $]$ para a construção transitiva de afetação, estamos dizendo que o sujeito dessa construção pode ser instanciado tanto por um agente, como em Miriam hidratou a pele de Livia, quanto por uma causa, como em o creme hidratou a pele de Livia ${ }^{11}$.

$\mathrm{O}$ fato de todos os cem verbos aceitarem um agente como argumento externo/ sujeito faz com que instanciem a construção que chamamos de "construção transitiva de afetação com instrumento", que está representada em (26), onde os dois SNs são papéis participantes e argumentais (GOLDBERG, 1995), enquanto o sintagma preposicionado (SP) é apenas papel argumental, ou seja, da construção.

\footnotetext{
${ }^{11}$ Verbos de afetação mais ampla aceitam apenas um agente na posição de sujeito, enquanto os verbos de mudança de estado aqui analisados aceitam tanto um agente como uma causa como sujeito. No entanto, isso não impede que eles sejam tratados como instanciações de uma mesma construção transitiva de afetação.
} 
(26) [SN Agente $\mathrm{V} \quad \mathrm{SN}$ Paciente $\mathrm{SP}$ Instrumento]

O capitão do mato chicoteou o escravo com um chicote de espinhos.

A arrumadeira espanou os móveis com uma flanela.

O povo apedrejou o bandido com pedras enormes.

O menino quebrou o vaso de flor com um martelo.

Miriam hidratou a pele de Lívia com um creme excelente.

Ana machucou Maria com uma navalha.

Até aqui, os verbos de afetação mais ampla e de mudança parecem se comportar sintaticamente da mesma forma. Contudo, apenas os verbos de mudança de estado participam do que chamamos de "construção intransitiva com sujeito paciente e adjunto causa", onde o SN é papel participante e argumental e o SP é apenas papel argumental.

(27) [SN Paciente V SP Causa]

$\mathrm{O}$ vaso de flor (se) quebrou com a queda.

A pele de Lívia (se) hidratou com a aplicação de produtos dermatológicos.

Maria (se) machucou com a queda.

\#O escravo (se) chicoteou com a ação do capitão do mato. $\rightarrow$ anômala na leitura incoativa

\#Os móveis (se) espanaram com o trabalho da arrumadeira. $\rightarrow$ anômala na leitura incoativa

\#O bandido (se) apedrejou com a raiva do povo. $\rightarrow$ anômala na leitura incoativa

Além disso, apenas os verbos de mudança de estado instanciam a "construção intransitiva com sujeito paciente" 12 , que nada mais é do que a construção em (27), porém sem o SP Causa.

(28) [SN Paciente V ]

$\mathrm{O}$ vaso de flor quebrou.

A pele de Lívia hidratou.

Maria machucou.

*O escravo chicoteou.

* Os móveis espanaram.

*O bandido apedrejou.

\footnotetext{
12 Perini (2008) chama esse tipo de construção no PB de construção ergativa.
} 
Visto isso, podemos perceber que tanto os verbos de afetação mais ampla quanto os de mudança de estado participam da construção transitiva de afetação (23) e da construção transitiva de afetação com instrumento (26). Isso decorre do fato de todos os verbos veicularem um tipo de afetação geral. No entanto, apenas os verbos de mudança de estado, que denotam uma afetação mais específica, instanciam as construções intransitivas mostradas em (27) e em (28), o que evidencia que o fato de um verbo acarretar uma mudança de estado para o seu argumento interno faz com que ele participe de construções específicas que não são instanciadas por verbos de afetação mais ampla. Com isso, fica clara a necessidade de se distinguir esses dois conceitos. Propomos a seguinte hierarquia entre as construções, onde também existe uma herança de traços entre elas:

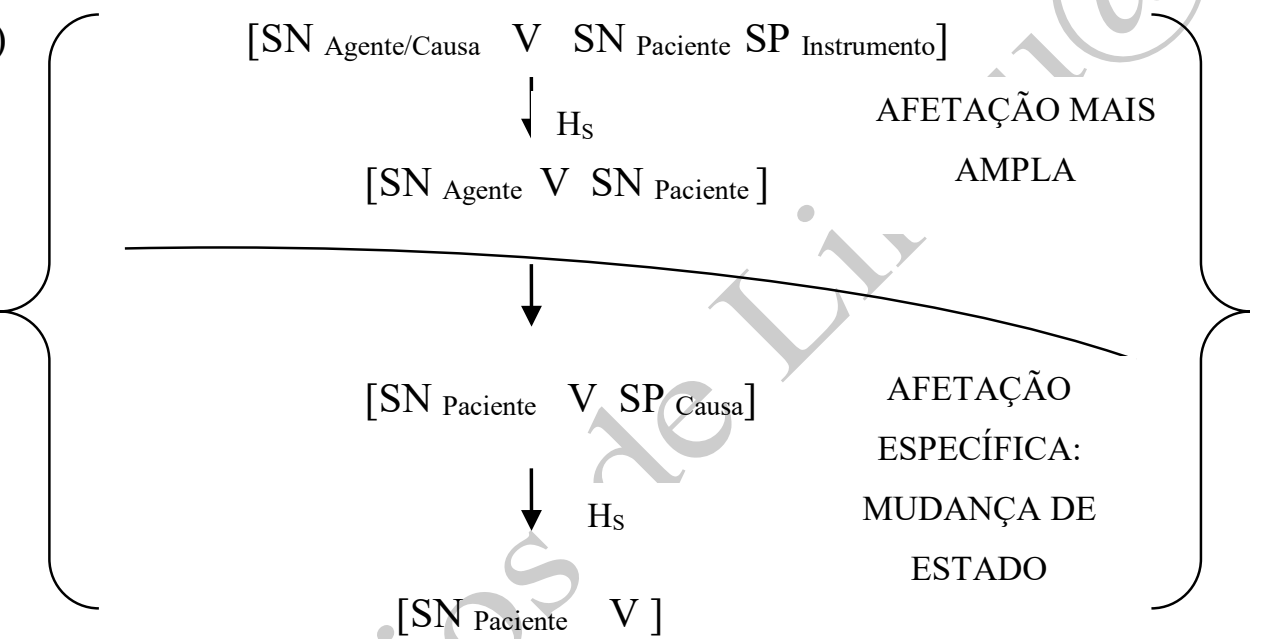

VERBOS DE AFETAÇÃO GERAL

A representação em (29) nos mostra que todas as construções analisadas neste artigo são características de verbos de afetação geral: verbos de afetação mais ampla e verbos de mudança de estado. Como esses últimos trazem consigo, além da noção de afetação mais ampla, uma afetação mais específica (sentido de mudança), eles participam tanto das construções do primeiro tipo quanto das do segundo. Já os verbos do tipo chicotear instanciam apenas as construções de afetação mais ampla, pois não denotam mudança de estado.

Baseadas em Goldberg (1995) e em Ferreira (2009), propomos que existe uma relação de Herança de Subparte $\left(\mathrm{H}_{\mathrm{S}}\right)$ entre as construções transitiva de afetação com instrumento e transitiva de afetação e entre as construções intransitiva com sujeito paciente e adjunto causa e intransitiva com sujeito paciente, de modo que a primeira contém a segunda e a terceira contém a quarta. 
Visto isso, acreditamos ter construbuído para uma melhor definição dos conceitos de afetação e mudança de estado na literatura, além de termos mostrado que tratar essas duas noções como sinônimas é algo que não se sustenta. Propomos, portanto, definir a afetação como uma propriedade semântica do verbo que faz com que ele atribua ao seu argumento interno o papel temático de paciente. Assim, toda vez que tivermos uma relação entre um agente e um paciente, teremos o conceito de afetação envolvido. Já a mudança de estado também deve ser tratada como uma propriedade semântica de um verbo que acarreta que o seu argumento interno, além de afetado (paciente), também muda de estado.

Nossa proposta se difere da de Beavers (2011), pois argumentamos a favor de um caminho inverso ao de sua escala de afetação. Enquanto o autor argumenta que a afetação pode ser definida de acordo com os tipos de mudança, nós propomos que toda mudança acarreta afetação, mas que nem toda afetação acarreta mudança. Isto é, se pensarmos nos conceitos hipônimo e hiperônimo ${ }^{13}$, temos que a mudança é o hipônimo, enquanto a afetação é o hiperônimo e não o contrário, como parece propor o autor.

Além disso, contrariamente ao proposto por Tenny (1987), que vê a afetação como uma propriedade que faz com que um verbo possa ser delimitado aspectualmente pelo seu argumento interno, transformando o evento em um acccomplishment, a nossa proposta abarca uma série de verbos que podem ter uma leitura télica ${ }^{14}$, mas que possuem o aspecto lexical de atividade, como em a arrumadeira espanou os móveis da casa em 30 minutos, onde o sintagma preposicionado em 30 minutos confere um ponto final à atividade de espanar os móveis (DOWTY, 1979).

\section{Considerações finais}

O nosso objetivo neste artigo foi analisar os conceitos semânticos de afetação e de mudança de estado, tidos como sinônimos na literatura, através das construções de estrutura

\footnotetext{
${ }^{13}$ A hiponímia é uma relação que existe entre palavras quando o sentido de uma está incluído no sentido de outra. Ao item mais específico damos o nome de hipônimo, enquanto chamamos o item mais geral de hiperônimo. A relação de hiponímia é assimétrica, pois o hipônimo contém seu hiperônimo, mas o contrário não é verdadeiro. (CANÇADO, 2013)

${ }^{14}$ Segundo Rothstein (2004), um evento télico é aquele que tem um ponto final ou uma meta a ser alcançada. A autora propõe que a telicidade é uma propriedade do sintagma verbal e também dos seus adjuntos, enquanto o aspecto lexical é inerente ao item lexical. Assim, construir uma casa e construir casas seriam, respectivamente, sintagmas verbais télico e atélico, ambos nucleados por um verbo de accomplishment. Da mesma forma, correr e correr três $\mathrm{km}$, são, respectivamente, sintagmas verbais atélico e télico, ambos nucleados por um verbo de atividade.
} 
argumental que os verbos que os veiculam podem participar. Baseadas em Fillmore (2003 [1970]) e em Cançado, Godoy e Amaral (2013), nossa hipótese inicial foi de que enquanto a afetação seria uma noção mais ampla, a mudança de estado seria um tipo mais específico de afetação, caracterizado por propriedades semânticas e sintáticas particulares.

De fato, concluímos que enquanto os verbos do tipo chicotear, que são de afetação mais ampla, participam apenas das construções transitiva de afetação com instrumento e transitiva de afetação, os verbos do tipo quebrar, que são de mudança de estado, participam, além dessas duas construções, de outras duas construções características dos verbos de afetação específica: a construção intransitiva com sujeito paciente e adjunto causa e a construção intransitiva com sujeito paciente. No entanto, todas essas construções são construções de afetação geral, uma vez que o conceito de mudança engloba o de afetação.

Assim, temos, como principal conclusão, que toda mudança acarreta afetação, mas que nem toda afetação acarreta mudança, o que contribui para a postulação de uma definição mais consistente para esses dois conceitos na Semântica Lexical.

Além disso, analisamos quatro construções do $\mathrm{PB}$ e propusemos uma relação hierárquica entre elas, de modo que acreditamos ter contribuído para a descrição dessa língua e também para o quadro teórico da Gramática de Construções como um todo, uma vez que Boas e Gonzálvez-García (2014) apontam a ausência de estudos dessa vertente nas línguas românicas. Contudo, ainda há outros verbos de afetação que precisam ser analisados, como os verbos do tipo bater (o menino bateu na menina) que pedem como argumento interno um sintagma preposicionado afetado e os demais tipos de verbos de mudança apresentados por Cançado, Godoy e Amaral (2013): verbos de mudança de lugar (hospitalizar, enjaular), verbos de mudança de posse (algemar, azulejar) e verbos de mudança de estado locativo (acomodar, enterrar).

\section{Referências Bibliográficas}

AMARAL, L. A alternância transitivo - intransitiva no português brasileiro: fenômenos semânticos. 2015. Tese (Doutorado em Linguística Teórica e Descritiva) - Poslin, Faculdade de Letras, UFMG, Belo Horizonte, 2015.

ANDERSON, M. Noun phrase structure. Ph.D dissertation, University of Connectivut, 1979.

BEAVERS, J. The structure of lexical meaning: why semantics really matters. Language, v.86, n 4, 2010, p.821-864. 
BEAVERS, J. On Affectedness. Natural Language and Linguistic Theory, v. 29, p. 335-370, 2011. crossref http://dx.doi.org/10.1007/s11049-011-9124-6

BLOOMFIELD, L. Language. New York: Henry Holt, 1933.

BOAS, H. C.; GONZÁLVEZ-GARCÍA, F. Applying constructional concepts to Romance languages. In: BOAS, H. C.; GONZÁLVEZ-GARCÍA, F. (eds.). Romance Perspectives on Construction Grammar. Amsterdam, Philadelphia: John Benjamins, 2014.

CANÇADO, M. Propriedades semânticas e posições argumentais. DELTA, v. 21, n. 1, 2005. p. 23-56. crossref http://dx.doi.org/10.1590/S0102-44502005000100002

CANÇADO, M. Verbal alternations in Brazilian Portuguese: a lexical semantic approach. Studies in Hispanic and Lusophone Linguistics, v. 3, n. 1, 2010, p. 77-111. crossref http://dx.doi.org/10.1515/shll-2010-1066

CANÇADO, M.; GODOY, L. Representação Lexical de Classes Verbais do PB. ALFA, v. 56, n. 1, 2012, p. 109-135. crossref $\mathrm{http}: / / \mathrm{dx}$.doi.org/10.1590/s1981-57942012000100006

CANÇADO, M. Manual de Semântica: noções básicas e exercícios. São Paulo: Contexto, 2013.

CANÇADO, M.; GODOY, L.; AMARAL, L. Catálogo de verbos do português brasileiro: classificação verbal segundo a decomposição de predicados. Vol I - Verbos de mudança. Belo Horizonte: Editora UFMG, 2013.

CANÇADO, M.; AMARAL, L.; MEIRELLES, L. Catálogo de verbos do português brasileiro: classificação verbal segundo a decomposição de predicados. Vol 2. em prep.

CHOMSKY, N. Syntactic Structures. The Hague: Mouton \& Co., 1957.

CIRÍACO, L. A construção transitiva em PB: associando a gramática de construções à decomposição lexical. Alfa, São Paulo, 58 (2): 401-416, 2014. crossref http://dx.doi.org/10.1590/1981-5794-1405-6

CUNHA, M. A. F. Polissemia construcional e convencionalização: o caso da construção ditransitiva. Revista do GEL, São Paulo, v. 10, n. 2, p. 77-99, 2013.

DOWTY, D. Word Meaning and Montague Grammar. Dordrecht: D. Reidel, 1979. crossref http://dx.doi.org/10.1007/978-94-009-9473-7

FERRARI, L. Modelos de gramática em lingüística cognitiva: princípios convergentes e perspectivas complementares. Cadernos de Letras da UFF - Dossiê: Letras e cognição, n 41, 149-165, 2010.

FERREIRA, M. A construção de Ação Rotineira no Português do Brasil: buscar menino no colégio, pular carnaval na Bahia e jogar lenha na fogueira. In: MIRANDA, N.; SALOMÃO, M. Construções do Português do Brasil: da gramática ao discurso. Belo Horizonte: UFMG, 2009. 
FILLMORE, C. The grammar of hitting and breaking. In: FILLMORE, C. Form and meaning in language: papers on semantics roles. Stanford: CSLI Publications, 2003a [1970]. p. 123139.

FILLMORE, C. Types of lexical information. In: FILLMORE, C. Form and meaning in language: papers on semantics roles. Stanford: CSLI Publications, 2003b [1971]. P. 141-173.

FILLMORE, C.; KAY, P.; O' CONNOR, M. Regularity and idiomaticity in grammatical constructions: The case of 'let alone', Language, v.64, 1988. p. 501-538. crossref http://dx.doi.org/10.2307/414531

GIVÓN, T. Syntax: an introduction. Amsterdam/Philadelphia: John Benjamins, 2001.

GOLDBERG, A. Constructions: A construction grammar approach to argument structure. Chicago, IL: University of Chicago Press, 1995.

HALE, K.; KEYSER, S. On argument structure and the lexical expression of syntactic relations. In: HALE, K.; KEYSER, S. The View from Building 20. Cambridge: MIT Press, 1993. p. 53109.

HALE, K.; KEYSER, S. Prolegomenon to a theory of argument structure. Cambridge: MIT Press, 2002.

HOPPER, P. J.; THOMPSON, S. A. Transitivity in Grammar and Discourse. In: Language, v 56, n 2, 1980. crossref http://dx.doi.org/10.1353/lan.1980.0017

JACKENDOFF, R. Semantics and Cognition. Cambridge: MIT Press, 1983.

JACKENDOFF, R. Semantic structures. Cambridge: MIT Press, 1990.

KIPARSKY, P. Word formation and the lexicon. In Proceedings of the Mid-America Linguistics Conference, ed. F. Ingeman. University of Kansas, 1982, 3-29.

KIPARSKY, P. Some consequences of Lexical Phonology. Phonology Yearbook 2, 1985, p. 85-138. crossref http://dx.doi.org/10.1017/S0952675700000397

LAKOFF, G. Irregularity in Syntax. New York: Holt, Rinehart and Winston, 1970.

LAKOFF, G. Women, fire, and dangerous things. Chicago: University of Chicago Press, 1987. cross ref http://dx.doi.org/10.7208/chicago/9780226471013.001.0001

LEVIN, B. English verb classes and alternations - a preliminary investigation. Chicago: The University of Chicago Press, 1993.

LEVIN, B. Objecthood: An Event Structure Perspective. Proceedings of CLS 35, volume 1: The Main Session, Chicago Linguistic Society, University of Chicago, Chicago, p. 223-247, 1999. 
LEVIN, B.; RAPPAPORT HOVAV, M. The Lexical Semantics of Verbs of Motion: The Perspective from Unaccusativity. In: ROCA, I. Thematic Structure: Its Role in Grammar. Berlin: Foris, 1992. p. 247-269. crossref http://dx.doi.org/10.1515/9783110872613.247

LEVIN, B.; RAPPAPORT HOVAV, M. Unaccusativity: at the syntax lexical semantics interface. Cambridge: MIT Press, 1995.

LEVIN,B.; RAPPAPORT HOVAV, M. Two Strucutures for Compositionally Derived Events. In: MATTHEWS, T.; STROLOVITCH, D. (Eds.). Proceedings of SALT 9. Ithaca: Cornell Linguistics Circle Publications, p. 199-223, 1999.

LEVIN, B.; RAPPAPORT HOVAV, M. Argument Realization. Cambridge: Cambridge University Press, 2005. crossref http://dx.doi.org/10.1017/СBO9780511610479

MCCAWLEY, J. The role of semantics in a grammar. In: BACH, E.; HARMS, R. Universals in Linguistic Theory. New York: Holt, Rinehart and Winston, 1968. p. 124-169.

MEIRELLES, L. As vantagens do uso da linguagem de decomposição em predicados primitivos em uma análise semântico-lexical das classes verbais do português brasileiro. Anais do SILEL. Volume 3, Número 1. Uberlândia: EDUFU, 2013.

MEIRELLES, L.; CANÇADO, M. Os verbos instrumentais no português brasileiro. Revista de Estudos Linguísticos Veredas, v. 19, n², 2015.

MORGAN, J. On arguing about semantics. Papers in Linguistics, v. 1, p. 49-70, 1969.

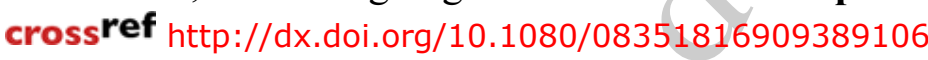

PARSONS, T. Events in the Semantics of English. Cambridge: MIT Press, 1990.

PERINI, M. A. Estudos de gramática descritiva: as valências verbais. São Paulo: Parábola, 2008.

PESETSKY, D. Zero syntax . Cambridge, Mass.: MIT Press, 1995.

PINKER, S. Learnability and Cognition: The acquisition of argument structure. Cambridge: MIT Press, 1989.

PUSTEJOVSKY, J. The Generative Lexicon. Cambridge: MIT Press, 1995.

RAPPAPORT HOVAV, M.; LEVIN, B. Building Verb Meanings. In: BUTT, M.; GEUDER, W. (eds.) The Projection of Arguments: Lexical and Syntactic Constraints. Stanford: CSLI Publications, p. 97-134, 1998a.

RAPPAPORT HOVAV, M.; LEVIN, B. Morphology and Lexical Semantics. In: SPENCER, A.; ZWICKY, A. (Eds.). Handbook of Morphology. Oxford: Blackwell, p. 248-271, 1998b. 
RAPPAPORT HOVAV, M.; LEVIN, B. An event structure account of English resultatives. Language 77, p. 766-797, 2001. crossref http://dx.doi.org/10.1353/lan.2001.0221

RAPPAPORT HOVAV, M.; LEVIN, B. Reflections on Manner/ Result Complementariry. In: RAPPAPORT HOVAV, M.; DORON, E.; SIZHEL, I. (Eds.). Lexical Semantics, Syntax and Event Structure. Oxford: Oxford University Press, p. 21-38, 2010. crossref http://dx.doi.org/10.1093/acprof:0so/9780199544325.003.0002

ROBERTS, I. The representation of implicit and dethematized subjects. Ph.D. Dissertation, University of Southern California, 1985.

ROTHSTEIN, S. Structuring events: a study in the semantics of lexical aspect. Oxford: Blackwell Publishing, 2004. crossref http://dx.doi.org/10.1002/9780470759127

TENNY, C. Grammaticalizing aspect and affectedness. PhD Disertation. Cambridge, MA: Dept. of Linguistics and Philosophy, Massachusetts Institute of Technology, 1987.

VENDLER, Z. Linguistics in Philosophy. Ithaca: Cornell, 1967.

WUNDERLICH, D. Cause and the structure of verbs. Linguistic Inquiry, v. 28, n. 1, p. 27-68, 1997.

WUNDERLICH, D. Lexical Decomposition in Grammar. In: WERNING, M.; HINZEN, W.; MACHERY, E. The Oxford Handbook of Compositionality. Oxford: Oxford University Press, 2012. p. 307-327. crossref http://dx,doi.org/10.1093/oxfordhb/9780199541072.013.0014

\section{Anexos}

Fonte dos dados: Cançado, Godoy, Amaral (2013), Meirelles e Cançado (2015), Cançado, Amaral e Meirelles (em prep.).

\section{Construção transitiva de afetação com instrumento:}

$$
\text { [SN } \text { Agente/Causa }_{\text {V }} \text { SNPaciente } \text { SP }_{\text {Instrumento] }}
$$

\section{Verbos de afetação mais ampla}
1) O escravo abanou o rei com uma folha de palmeira.
2) $\mathrm{O}$ açougueiro afiou a faca com uma pedra apropriada.
3) O jardineiro aguou a roseira com uma mangueira.
4) $\mathrm{O}$ artesão amolou a tesoura com uma pedra.
5) $\mathrm{O}$ jardineiro aparou a grama com um tesourão.
6) O povo apedrejou Maria Madalena com pedras de todos os tamanhos.
7) O bombeiro apertou o parafuso com uma chave de fenda.
8) $\mathrm{O}$ aluno apontou o lápis com um canivete.
9) O servente areou a panela com uma esponja de aço.
10) O médico auscultou o coração do paciente com um estetoscópio.
11) O Seu Felício barbeou o freguês com uma navalha.
12) A cozinheira bateu o ovo com um garfo.
13) Israel bombardeou a Palestina com bombas nucleares. 
14) O coveiro cavou o chão com uma pá.

15) O patrão chicoteou o empregado com um chicote de espinhos.

16) A cozinheira coou o leite com um pano de prato.

17) A manicure cortou a unha da cliente com uma tesoura.

18) A esteticista depilou a perna da cliente com cera quente.

19) O bandido enforcou o inimigo com um pedaço de pano.

20) A cozinheira escaldou o frango com água fervente.

21) O arqueólogo escavou o terreno com uma picareta.

22) A faxineira esfregou o chão com a vassoura.

23) O servente espanou os móveis com uma flanela.

24) A cozinheira espetou a carne com um garfo.

25) A cozinheira espremeu a laranja com uma centrífuga.

26) A enfermeira higienizou a sala de cirurgia com álcool.

27) $O$ joalheiro lapidou a pedra de diamante com uma ferramenta importada.

28) A faxineira limpou a sala com um pano de chão.

29) A faxineira lustrou o móvel da sala com um pano seco.

30) O operário marretou a viga de concreto com uma marreta de ferro.

31) Ricardo martelou o prego com um martelo de ferro.

32) A Carla palitou o dente da criança com um palito de madeira.

33) A dona da loja passou o vestido de seda com o ferro.

34) Maria peneirou o arroz com uma peneira de plástico.

35) A cozinheira picou o tomate com uma faca.

36) O estagiário picotou o papel com uma tesoura.

37) $\mathrm{O}$ artista pincelou o quadro com um pincel de nylon.

38) O jardineiro podou a roseira com uma tesoura.

39) O moço poliu o carro com cera.

40) A cabeleireira pranchou o cabelo da menina com uma prancha de íons.

41) A cozinheira ralou o coco com um processador.

42) O jardineiro regou as plantas com a mangueira.

43) O lenhador serrou a madeira com uma serra elétrica.

44) A cozinheira socou o alho com o cabo da faca.

45) O chef sovou a massa do biscoito com um rolo.

46) O homem torceu o arame com um alicate.

47) O funcionário do pet shop tosou o cachorro com um barbeador.

48) O fazendeiro tosquiou as ovelhas com uma tesoura.

49) O chef triturou as nozes com um socador de alho.

50) O servente varreu o chão da escola com uma vassoura de pet.

\section{Verbos de mudança de estado}

1) O João abriu a janela com uma chave de fenda.

2) O João achatou a lata de refrigerante com um martelo.

3) A esteticista afinou a sobrancelha da Maria com uma pinça.

4) A Maria alisou os cabelos da Joana com a chapinha.

5) O cabeleireiro amaciou os cabelos da Maria com um creme.

6) A esteticista amoleceu a cera com água quente.

7) O médico anestesiou a perna do João com um analgésico forte.

8) O menino arranhou o disco com uma faca.

9) O João arrebentou a porta com um pé de cabra.

10) O cabeleireiro cacheou o cabelo da Maria com o babyliss.

11) O João cegou o cavalo com uma faca.

12) O criminoso contaminou a Maria com uma agulha suja.

13) O hacker corrompeu o arquivo com um vírus terrível.

14) O bandido cortou o rosto da Maria com um canivete.

15) O médico curou a paciente com um antibiótico.

16) O João deformou a estátua com um martelo.

17) O ourives derreteu a jóia com um maçarico.

18) A criança descascou a parede com um canivete. 
19) O cozinheiro descongelou o frango com água morna.

20) O bombeiro desentupiu a pia com o desentupidor.

21) O menino levado desfiou a meia da Maria com uma agulha.

22) O João desligou a televisão com controle remoto.

23) A Maria destrancou a janela com a chave.

24) O químico dissolveu a solução com um catalisador.

25) O decorador embelezou a casa com flores.

26) O cabeleireiro ensebou o cabelo da Maria com um creme.

27) O João entortou a chapa com um martelo.

28) A menina travessa entupiu a pia com um pedaço de pano.

29) O terrorista envenenou a população com gás tóxico.

30) A enfermeira esterilizou a mesa de cirurgia com um produto químico.

31) O menino estragou o sofá com uma tesoura.

32) A esteticista hidratou a pele da Maria com um produto.

33) O funcionário iluminou a sala com uma lanterna.

34) $\mathrm{O}$ atirador imobilizou o monstro com um dardo envenenado.

35) $\mathrm{O}$ terrorista intoxicou as pessoas com remédios para animais.

36) O colega lambuzou as mãos do menino com uma colher de mel.

37) O João machucou a Maria com uma tesoura.

38) A estilista manchou o tecido com tinta.

39) O policial paralisou o bandido com a arma de choque.

40) $\mathrm{O}$ vilão poluiu a cidade com gás tóxico.

41) A soprano quebrou a taça de cristal com um martelo.

42) O menino queimou a menina com um isqueiro.

43) O menino rasgou a meia-calça da mulher com uma faca.

44) A passadeira secou a roupa com o ferro.

45) O arqueólogo segmentou a rocha com um laser.

46) O menino sujou a calçada com um spray.

47) A cozinheira torrou o pão com a chapa.

48) A Maria trancou a porta com uma chave.

49) O menino trincou o vidro do carro com uma pedra.

50) A lavadeira umedeceu os tapetes com um borrifador.

Construção transitiva de afetação:

$$
\text { [SNAgente/Causa V SN Paciente] }
$$

Verbos de afetação mais ampla

1) O escravo abanou o rei,

2) $\mathrm{O}$ açougueiro afiou a faca.

3) O jardineiro aguou a roseira.

4) $O$ artesão amolou a tesoura.

5) O jardineiro aparou a grama.

6) O povo apedrejou Maria Madalena.

7) O bombeiro apertou o parafuso.

8) O aluno apontou o lápis.

9) O servente areou a panela.

10) O médico auscultou o coração do paciente.

11) O Seu Felício barbeou o freguês.

12) A cozinheira bateu o ovo.

13) Israel bombardeou a Palestina.

14) O coveiro cavou o chão.

15) O patrão chicoteou o empregado.

16) A cozinheira coou o leite.

17) A manicure cortou a unha da cliente.

18) A esteticista depilou a perna da cliente.

19) O bandido enforcou o inimigo.

20) A cozinheira escaldou o frango. 
21) O arqueólogo escavou o terreno.

22) A faxineira esfregou o chão.

23) O servente espanou os móveis.

24) A cozinheira espetou a carne.

25) A cozinheira espremeu a laranja.

26) A enfermeira higienizou a sala.

27) O joalheiro lapidou a pedra de diamante.

28) A faxineira limpou a sala.

29) A faxineira lustrou o móvel da sala.

30) O operário marretou a viga de concreto.

31) Ricardo martelou o prego.

32) A Carla palitou o dente da criança.

33) A dona da loja passou o vestido de seda.

34) Maria peneirou o arroz.

35) A cozinheira picou o tomate.

36) O estagiário picotou o papel.

37) $\mathrm{O}$ artista pincelou o quadro.

38) O jardineiro podou a roseira.

39) O moço poliu o carro.

40) A cabeleireira pranchou o cabelo da menina.

41) A cozinheira ralou o coco.

42) O jardineiro regou as plantas.

43) O lenhador serrou a madeira.

44) A cozinheira socou o alho.

45) O chef sovou a massa do biscoito.

46) O homem torceu o arame.

47) O funcionário do pet shop tosou o cachorro.

48) O fazendeiro tosquiou as ovelhas.

49) $\mathrm{O}$ chef triturou as nozes.

50) O servente varreu o chão da escola.

\section{Verbos de mudança de estado}

1) O João/ a ventania abriu a janela.

2) O João/ a pancada achatou a lata de refrigerante.

3) A esteticista/ o tratamento dermatológico afinou a sobrancelha da Maria.

4) A Maria/ o tratamento alisou os cabelos da Joana.

5) O cabeleireiro/ a hidratação amaciou os cabelos da Maria.

6) A esteticista/ o calor amoleceu a cera.

7) O médico/ a pancada anestesiou a perna do João.

8) O menino/ o uso frequente arranhou o disco.

9) O João/ o chute do João arrebentou a porta.

10) O cabeleireiro/ a umidade cacheou o cabelo da Maria.

11) O João/a doença cegou o cavalo.

12) O criminoso/ o mau uso da seringa contaminou a Maria.

13) O hacker/ a instalação do programa corrompeu o arquivo.

14) O bandido/ o acidente cortou o rosto da Maria.

15) O médico/ a cão do antibiótico curou o paciente.

16) O João/ o aumento da temperatura deformou a estátua.

17) $\mathrm{O}$ ourives/ o calor do incêndio derreteu a joia.

18) A criança/ a umidade descascou a parede.

19) O cozinheiro/ o calor do fogão descongelou o frango.

20) O bombeiro/ a pressão da água desentupiu a pia.

21) O menino levado/a unhada do gato desfiou a meia da Maria.

22) O João/ o raio que caiu desligou a televisão.

23) A Maria/ a ventania destrancou a janela.

24) O químico/ o calor dissolveu a solução.

25) O decorador/ a nova decoração embelezou a casa. 
26) O cabeleireiro/ a gordura da cozinha ensebou o cabelo da Maria.

27) O João/ o chute do João entortou a chapa.

28) A menina travessa/ o excesso de sujeira entupiu a pia.

29) O terrorista/ o vazamento de gás tóxico envenenou a população.

30) A enfermeira/ a aplicação do produto esterilizou a mesa de cirurgia.

31) O menino/ a exposição ao sol estragou o sofá.

32) A esteticista/ a aplicação do creme hidratou a pele da Maria.

33) O funcionário/ a entrada da luz iluminou a sala.

34) $\mathrm{O}$ atirador/ o envenenamento imobilizou o monstro.

35) $\mathrm{O}$ terrorista/ a dedetização intoxicou as pessoas.

36) O colega/ a brincadeira no barro lambuzou as mãos do menino.

37) O João/ a queda machucou a Maria.

38) A estilista/ a lavagem a seco manchou o tecido.

39) O policial/ o susto paralisou o bandido.

40) O vilão/ o acúmulo de lixo poluiu a cidade.

41) A soprano/ o grito da soprano quebrou a taça de cristal.

42) $\mathrm{O}$ menino/ a brincadeira com o fogo queimou a menina.

43) $\mathrm{O}$ menino/ o tombo rasgou a meia-calça da mulher.

44) A passadeira/ o calor secou a roupa.

45) O arqueólogo/ o curso da água segmentou a rocha.

46) O menino/ a ventania sujou a calçada.

47) A cozinheira / o calor excessivo do forno torrou o pão.

48) A Maria/ a ventania trancou a porta.

49) O menino/ o acidente trincou o vidro do carro.

50) A lavadeira/ a chuva forte umedeceu os tapetes.

Construção intransitiva com sujeito paciente e SP causa:

\section{Verbos de mudança de estado}

1) A janela abriu com a ventania.

2) A lata de refrigerante achatou com a pancada.

3) A sobrancelha da Maria afinou com o tratamento dermatológico.

4) Os cabelos da Joana alisaram com o tratamento.

5) Os cabelos da Maria amaciaram com a hidratação.

6) A cera amoleceu com o calor.

7) A perna do João anestesiou com a pancada.

8) O disco arranhou com o uso freqüente.

9) A porta arrebentou com o chute do João.

10) O cabelo da Maria cacheou com a umidade.

11) O cavalo cegou com a doença.

12) A Maria contaminou com o mau uso da seringa.

13) $\mathrm{O}$ arquivo corrompeu com a instalação do programa.

14) O rosto da Maria cortou com o acidente.

15) A paciente curou com a ação do antibiótico.

16) A estátua deformou com o aumento da temperatura.

17) A jóia derreteu com o calor do incêndio.

18) A parede descascou com a umidade

19) O frango descongelou com o calor do fogão.

20) A pia desentupiu com a pressão da água.

21) A meia da Maria desfiou com a unhada do gato.

22) A televisão desligou com o raio que caiu.

23) A solução dissolveu com o calor.

24) A janela destrancou com a ventania.

25) A casa embelezou com a nova decoração. 
26) O cabelo da Maria ensebou com a gordura da cozinha.

27) A pia entupiu com o excesso de sujeira.

28) A chapa entortou com o chute do João.

29) A população envenenou com o vazamento de gás tóxico.

30) A mesa de cirurgia esterilizou com a aplicação do produto.

31) O sofá estragou com a exposição ao sol.

32) A pele da Maria hidratou com a aplicação do creme.

33) A sala iluminou com a entrada da luz.

34) O monstro imobilizou com o envenenamento.

35) As pessoas intoxicaram com a dedetização.

36) As mãos do menino lambuzaram com a brincadeira no barro.

37) A Maria machucou com a queda.

38) O tecido manchou com a lavagem a seco.

39) O bandido paralisou com o susto.

40) A cidade poluiu com o acúmulo de lixo.

41) A taça de cristal quebrou com o grito da soprano.

42) A menina queimou com a brincadeira com fogo.

43) A meia-calça da mulher rasgou com o tombo.

44) A roupa secou com o calor.

45) A rocha segmentou com o curso da água.

46) A calçada sujou com a ventania.

47) O pão torrou com o calor excessivo do forno.

48) A porta trancou com a ventania.

49) O vidro do carro trincou com o acidente.

50) Os tapetes umedeceram com a chuva forte.

\section{Construção intransitiva com sujeito paciente:}

\section{Verbos de mudança de estado}

1) A janela abriu.

2) A lata de refrigerante achatou.

3) A sobrancelha da Maria afinou.

4) Os cabelos da Joana alisaram.

5) Os cabelos da Maria amaciaram.

6) A cera amoleceu.

7) A perna do João anestesiou.

8) O disco arranhou.

9) A porta arrebentou.

10) O cabelo da Maria cacheou.

11) O cavalo cegou.

12) A Maria contaminou.

13) $\mathrm{O}$ arquivo corrompeu.

14) O rosto da Maria cortou.

15) A paciente curou.

16) A estátua deformou.

17) A jóia derreteu.

18) A parede descascou.

19) O frango descongelou.

20) A pia desentupiu.

21) A meia da Maria desfiou.

22) A televisão desligou.

23) A janela destrancou.

24) A solução dissolveu.

25) A casa embelezou.

$$
\text { [SNPaciente V] }
$$


26) O cabelo da Maria ensebou.

27) A chapa entortou.

28) A pia entupiu.

29) A população envenenou.

30) A mesa de cirurgia esterilizou.

31) O sofá estragou.

32) A pele da Maria hidratou.

33) A sala iluminou.

34) O monstro imobilizou.

35) As pessoas intoxicaram.

36) As mãos do menino lambuzaram.

37) A Maria machucou.

38) O tecido manchou.

39) O bandido paralisou.

40) A cidade poluiu.

41) A taça de cristal quebrou.

42) A menina queimou.

43) A meia-calça da mulher rasgou.

44) A roupa secou.

45) A rocha segmentou.

46) A calçada sujou.

47) O pão torrou.

48) A porta trancou.

49) O vidro do carro trincou.

50) Os tapetes umedeceram. 